\title{
Evaluation of the national Cleanyourhands campaign to reduce Staphylococcus aureus bacteraemia and Clostridium difficile infection in hospitals in England and Wales by improved hand hygiene: four year, prospective, ecological, interrupted time series study
}

\author{
(c) (1) ()
}

Sheldon Paul Stone senior lecturer, stroke physician, and general physician for older people ${ }^{1}$, Christopher Fuller project manager and nursing research fellow ${ }^{2}$, Joan Savage research associate ${ }^{2}$, Barry Cookson director ${ }^{3}$, Andrew Hayward senior lecturer ${ }^{2}$, Ben Cooper mathematical modeller ${ }^{510}$, Georgia Duckworth director ${ }^{4}$, Susan Michie professor of health psychology ${ }^{6}$, Miranda Murray consultant scientist ${ }^{4}$, Annette Jeanes consultant nurse in infection control ${ }^{7}$, J Roberts emeritus professor of economics of infectious disease ${ }^{8}$, Louise Teare consultant microbiologist and infection control doctor ${ }^{9}$, Andre Charlett head of department ${ }^{10}$

${ }^{1}$ Royal Free Campus, University College London Medical School, London NW3 2PF, UK; ${ }^{2}$ Research Department of Infection and Population Health, Royal Free Hospital, London; ${ }^{3}$ Laboratory of HealthCare Associated Infection, Health Protection Agency, London; ${ }^{4}$ Department of Healthcare Associated Infection and Antimicrobial Resistance, Health Protection Agency, London; ${ }^{5}$ Tropical Medicine Research Unit, Mahidol University, Bangkok, Thailand; ${ }^{6}$ Department of Psychology, University College London; ${ }^{7}$ Department of Microbiology, University College London Hospitals, London; ${ }^{8}$ Department of Public Health and Policy, London School of Hygiene and Tropical Medicine, London ; ${ }^{9}$ Department of Microbiology, Mid-Essex NHS Trust, Chelmsford, Essex, UK; ${ }^{10}$ Department of Statistics, Modelling, and Economics, Health Protection Agency

\begin{abstract}
Objective To evaluate the impact of the Cleanyourhands campaign on rates of hospital procurement of alcohol hand rub and soap, report trends in selected healthcare associated infections, and investigate the association between infections and procurement.

Design Prospective, ecological, interrupted time series study from 1 July 2004 to 30 June 2008.

Setting 187 acute trusts in England and Wales.

Intervention Installation of bedside alcohol hand rub, materials promoting hand hygiene and institutional engagement, regular hand hygiene audits, rolled out nationally from 1 December 2004.

Main outcome measures Quarterly (that is, every three months) rates for each trust of hospital procurement of alcohol hand rub and liquid soap; Staphylococcus aureus bacteraemia (meticillin resistant (MRSA) and meticillin sensitive (MSSA)) and Clostridium difficile infection for each trust. Associations between procurement and infection rates
\end{abstract}

assessed by mixed effect Poisson regression model (which also accounted for effect of bed occupancy, hospital type, and timing of other national interventions targeting these infections).

Results Combined procurement of soap and alcohol hand rub tripled from 21.8 to $59.8 \mathrm{~mL}$ per patient bed day; procurement rose in association with each phase of the campaign. Rates fell for MRSA bacteraemia (1.88 to 0.91 cases per 10000 bed days) and $C$ difficile infection (16.75 to 9.49 cases). MSSA bacteraemia rates did not fall. Increased procurement of soap was independently associated with reduced $C$ difficile infection throughout the study (adjusted incidence rate ratio for $1 \mathrm{~mL}$ increase per patient bed day $0.993,95 \%$ confidence interval 0.990 to $0.996 ; \mathrm{P}<0.0001)$. Increased procurement of alcohol hand rub was independently associated with reduced MRSA bacteraemia, but only in the last four quarters of the study $(0.990,0.985$ to $0.995 ; P<0.0001)$. Publication of the Health Act 2006 was strongly associated with reduced MRSA bacteraemia $(0.86,0.75$ to $0.98 ; P=0.02)$ and $C$ difficile infection $(0.75,0.67$ to $0.84 ; P<0.0001)$. Trust visits by 
Department of Health improvement teams were also associated with reduced MRSA bacteraemia $(0.91,0.83$ to $0.99 ; \mathrm{P}=0.03)$ and $C$ difficile infection $(0.80,0.71$ to $0.90 ; P=0.01)$, for at least two quarters after each visit.

Conclusions The Cleanyourhands campaign was associated with sustained increases in hospital procurement of alcohol rub and soap, which the results suggest has an important role in reducing rates of some healthcare associated infections. National interventions for infection control undertaken in the context of a high profile political drive can reduce selected healthcare associated infections.

\section{Introduction}

Healthcare associated infections can spread from patient to patient through the contamination of healthcare workers' hands by infectious organisms. ${ }^{1}$ Improving hand hygiene reduces infection in a wide variety of settings. ${ }^{2}$ Following government and public concern at reported high levels of meticillin resistant Staphylococcus aureus (MRSA) bacteraemia, meticillin sensitive $S$ aureus (MSSA) bacteraemia, and Clostridium difficile infection, ${ }^{4-6}$ and low levels of hand hygiene compliance, ${ }^{7-9}$ the Cleanyourhands campaign ${ }^{10}$ was rolled out in 2004 in England and Wales to healthcare workers in all acute National Health Service (NHS) hospital trusts.

The main components of the campaign comprised provision of alcohol hand rub at the bedside, distribution of posters reminding healthcare workers to clean their hands, regular audit and feedback of compliance, and provision of materials empowering patients to remind healthcare workers to clean their hands. Trusts were to order soap and alcohol hand rub through the central NHS supply agencies, which had ensured that all products met efficacy, safety, and acceptability standards. The campaign was centrally funded by the Department of Health and coordinated by the National Patient Safety Agency, which rolled out the campaign to all acute trusts from December 2004 to June 2005. The campaign was refreshed at the end of June 2006, ${ }^{11}$ and relaunched with new posters in October 2007. The development, roll out, and long term coordination of the campaign is described in full elsewhere. ${ }^{10-12}$

Although the main components of the campaign were interventions reported to be effective at the level of the single hospital or individual unit, ${ }^{13-15}$ such interventions had not previously been implemented or evaluated at a national level. ${ }^{16}$ The Department of Health funded an independent evaluation of the campaign, which faced methodological challenges common to other recent studies evaluating large scale public health interventions. ${ }^{17}{ }^{18}$ Firstly, the policy requirement to roll out the campaign quickly precluded the use of randomised or stepped wedge designs and prevented collection of data that were not routinely available, such as hand hygiene compliance. Secondly, other national interventions or initiatives that were not planned or anticipated at the start of the study but which targeted reduction of MRSA bacteraemia or $C$ difficile infection were implemented during the study. These interventions included the Saving Lives campaign (a programme of implementing infection control care bundles within a clinical governance framework), ${ }^{19}$ the setting of a national target for MRSA bacteraemia, publication of the Health Act 2006 (legislation of statutory criteria for infection control), ${ }^{20}$ and visits to trusts by Department of Health improvement teams to reinforce delivery of the Saving Lives campaign (table $1 \Downarrow$ ).

To meet these challenges, the study used a prospective, ecological, time series design, suitable for evaluating public health interventions, ${ }^{21}$ using existing trust level data for the main outcomes and measurement of potential confounders. Because of the absence of data for hand hygiene compliance, we used available trust level data for procurement of alcohol hand rub and soap as a proxy. These data are considered a more practical and objective way to assess quantitative change in hand hygiene between hospitals ${ }^{22}$ and better indicate 24 hour, seven day a week use of alcohol hand rub and soap. ${ }^{23}{ }^{24}$ In addition, the original study on which the campaign was based had shown a rise in both compliance and procurement. ${ }^{14} \mathrm{We}$ dealt with the potentially confounding effects of other national interventions by collecting available trust level information on these interventions to incorporate into the overall analysis.

We aimed to assess the Cleanyourhands campaign's impact on hospital procurement of soap and alcohol hand rub, to report on trends in rates of MRSA and MSSA bacteraemia and $C$ difficile infection, and to determine an association between infection and procurement rates.

\section{Methods}

\section{Study design, phases, and setting}

We used a prospective, ecological, interrupted time series design that routinely collected data at the trust level. The study was designed and reported according to standard guidelines for infection control interventions. ${ }^{25}$ The campaign was applied to the first six trusts in December 2004 and to the remaining 181 by the end of June 2005 in four waves (table 1). Since the campaign was applied to so few trusts in December 2004 (most of which had been involved in the national pilot study ${ }^{15}$ ), national roll out was considered to have begun on 1 January 2005, with the study divided into three predefined phases: 1 July 2004 to 31 December 2004 (six months before roll out of the campaign), 1 January to 30 June 2005 (campaign roll out), and 1 July 2005 to 30 June 2008 (36 months after roll out of the campaign).

\section{Outcome measures}

Monthly procurement data (volume, $\mathrm{mL}$ ) for alcohol hand rub and liquid soap for each individual trust served as a proxy marker for usage and compliance. We collected this information prospectively from central suppliers in England (NHS Supply Chain) and Wales (Welsh Health Supplies), and smoothed out the effects of procurement spikes due to infrequent bulk ordering (see below).

To record infection rates, the study had access to the database for the national mandatory reporting scheme in England, held by the Health Protection Agency. This database categorised hospital trusts as acute, teaching, or specialist. It also collected count data every quarter (or three months) for hospital acquired (that is, $>48 \mathrm{~h}$ after admission) MRSA bacteraemia (at all ages), $C$ difficile infection (at age $\geq 65$ years), and MSSA bacteraemia (although MSSA data were not differentiated into hospital acquired and community acquired categories). We did not use data for Welsh hospitals because it was not possible to separate data for acute trusts from those for primary care and community hospitals.

For each trust, we estimated the total number of occupied bed days for each month or quarter using national KH03 data. Since data for $C$ difficile infection rates were only for patients older than 65 years, we could use these data to provide only an estimate of incidence, because the KH03 data used were not age related.

In relation to potential confounders during the study period, other mandatory national interventions were introduced that targeted the same infections as the Cleanyourhands campaign (table 1). The study recorded the dates of the announcement of 
the MRSA target, and of publication of the Health Act $2006^{24}$ and the individual care bundles for the Saving Lives campaign, and the date that each individual trust registered with the Saving Lives campaign and received visits by a Department of Health improvement team. We collected trust level data for mupirocin use, a surrogate marker for MRSA screening and decolonisation, via Intercontinental Marketing Services Health for Trusts. Data for average length of stay were obtained from hospital episode statistics.

\section{Statistical analysis}

Smoothed trends in monthly procurement data were estimated by applying a series of median smoothers to the time series of alcohol hand rub and soap for each trust, and expressed as $\mathrm{mL}$ per patient bed day for soap, alcohol hand rub, and both in each quarter. We excluded 23 trusts that had a sequence of at least 18 months with missing data, and 44 trusts that had at least two years of missing soap data or were supplied by another source. We assessed temporal trends in a mixed effects, linear regression analysis with usage per bed day as the outcome variable. We used the Cleanyourhands campaign's roll out, year 2 refreshment of the campaign, year 3 relaunch, and quarter as fixed effects and the trust as a random effect. The associations between procurement rates and improvement team visits (differentiating between visits for MRSA bacteraemia and $C$ difficile infection) or publication of the Health Act 2006 were assessed, accounting for temporal trends in procurement and trust type.

We expressed trends in quarterly infection rates as cases per 10 000 patient bed days for 170 English acute trusts, excluding five because mergers and reorganisations disrupted continuity of data. Four children's trusts were excluded from the $C$ difficile infection rates because their patients were too young.

The quarterly counts of incident infections were used as the outcome variables in a series of mixed effects Poisson regression models to assess the associations with estimated concurrent procurement of hand hygiene consumables. We assessed the consistency of the associations between infections and consumables by incorporating an interaction between quarters and consumables, and included the potential confounders (listed above) as fixed effects. To allow for a lag in the effectiveness in some of the above interventions, we categorised the data to include periods immediately before and after intervention. We included the quarter and trust in the regression models as random effects, to allow for temporal trends. The natural logarithm of the estimated number of occupied beds was used as an offset in the regression model to directly obtain estimates of incidence rate ratios. We fitted all models to the data using the xtmepoisson command within Stata 11. The effect of trust type on the procurement association was explored using a three way interaction (type, procurement, quarter).

\section{Results}

\section{Trends in procurement of alcohol hand rub and soap}

Average procurement of alcohol hand rub rose throughout the study, from 3.4 to $26.0 \mathrm{~mL}$ per patient bed day but not at the expense of soap procurement, which also rose from 17.4 to 33.8 $\mathrm{mL}$ per patient bed day (fig $1 \Downarrow$ ). Combined procurement almost tripled, from 21.8 to $59.8 \mathrm{~mL}$ per patient bed day. The regression model showed that the rate of change increased significantly during the roll out of the Cleanyourhands campaign (average absolute increase in procurement per quarter $1.83(95 \%$ confidence interval 1.60 to 2.07) for alcohol hand rub, 0.99 (0.41 to 1.56$)$ for soap), after campaign refreshment (1.4 (1.10 to 1.70$), 1.22$ (0.38 to 2.07$)$ ), and after campaign relaunch (1.28 (1.16 to 1.41$), 1.08$ (0.69 to 1.48$)$ ). The average increase in procurement of alcohol hand rub was notably higher than that of soap only in the rollout phase.

\section{Trends in infection rates}

Data were available from 170 trusts for MRSA bacteraemia and from 165 for MSSA bacteraemia and $C$ difficile infection. The rate of MRSA bacteraemia fell from a peak of 1.88 to 0.91 cases per 10000 bed days (fig $2 \Downarrow$ ). Funnel and scatter plots showed no evidence of particular trusts making disproportionately large contributions to the fall (web appendix). The MSSA bacteraemia rate rose slightly from 2.67 per 10000 bed days to a peak of 3.23 , before falling to 3.0 at the end of the study. The estimated rate of $C$ difficile infection fell from a peak of 16.75 to 9.49 cases per 10000 bed days, being subject initially to seasonal peaks in the first quarter of each year, which disappeared in the last year of the study (fig $3 \Downarrow$ ).

\section{Associations between infection and procurement rates}

Procurement data for alcohol hand rub and soap from 116 trusts were collected, and contributed 1727 quarters of observations to the model for MRSA bacteraemia, with 115 and 112 trusts contributing 1685 and 1658 quarters of observations, respectively, to the models for MSSA bacteraemia and $C$ difficile infection, respectively. The remaining quarters had at least one predictor variable missing.

We found a significant independent association between soap procurement and $C$ difficile infection throughout the study, with each additional $\mathrm{mL}$ of soap per patient bed day associated with a $0.7 \%$ (95\% confidence interval $4 \%$ to $10 \%$ ) reduction in $C$ difficile infection $(\mathrm{P}<0.0001$; table $2 \Downarrow)$. Thus, for an increase of $10 \mathrm{~mL}$ in soap procurement per bed day, the estimated incident rate ratio would be 0.993 (95\% confidence interval 0.99 to 0.996$)^{10}$, which is 0.929 (0.904 to 0.961$)$ or a $7.1 \%(3.9 \%$ to $9.6 \%$ ) relative reduction in infection rates. This association did not change with time, after comparing overall estimates in each of the four years of the study (likelihood ratio test; $\chi^{2}=1.89$, $\mathrm{df}=3, \mathrm{P}=0.6$ ).

Each additional $\mathrm{mL}$ of alcohol hand rub procured per patient bed day was associated with a rise in $C$ difficile infection which changed over time, being most marked during periods of high incidence of $C$ difficile infection. Further analyses showed strong correlations between soap and alcohol hand rub procurement (web appendix). When included separately in a simplified model, each consumable was associated with a reduction in $C$ difficile infection. Inclusion of both consumables removed the association with alcohol hand rub, suggesting that only soap was independently associated with reduced $C$ difficile infection.

The association of alcohol hand rub with MRSA bacteraemia changed over time, becoming significant only in each of the last four quarters of the study (fig $4 \Downarrow$ ), with an estimated reduction in MRSA bacteraemia of $1 \%$ (95\% confidence interval $5 \%$ to $15 \%$ ) for each additional $\mathrm{mL}$ used per bed day (table $3 \Downarrow$ ). Thus, for every increase in alcohol hand rub procurement of 10 $\mathrm{mL}$ per bed day, the estimated incident rate ratio would be 0.99 $(0.985 \text { to } 0.995)^{10}$, which is 0.904 (0.857 to 0.951$)$ or a $9.6 \%$ $(4.9 \%$ to $14.3 \%)$ relative reduction in infection rates.

Although MSSA bacteraemia was not associated with alcohol hand rub procurement, we saw a significant association between increasing use of liquid soap and increasing MSSA bacteraemia (incident rate ratio 1.0029 (95\% confidence interval 1.001 to 1.004); $\mathrm{P}=0.0001$ ), for each extra $\mathrm{mL}$ of soap used per bed day, 
which could have been due to collinear increasing temporal trends. Publication of the Health Act 2006 was strongly associated with reductions of both MRSA bacteraemia and $C$ difficile infection, as were Department of Health improvement team visits, two or more quarters after each visit (tables 2 and 3). We saw no associations between these visits and procurement rates. Publication of the Health Act 2006 was associated with a significant increase in the procurement rate of alcohol hand rub $(0.68 \mathrm{~mL}$ per bed day $(95 \%$ confidence interval 0.37 to $0.99)$ ) and soap (1.055 (0.32 to 1.79)), after comparing the average quarterly rate of rise in $\mathrm{mL}$ per bed day in the period after the roll out (but before publication of the act) with the period after publication of the act.

We found no other associations of infection rates with procurement data, phases of the campaign, or any other intervention or potential confounder, with the three way interaction between trust category, procurement data, and quarter proving non-significant for MRSA bacteraemia $\left(\chi^{2}=37.70\right.$, $\mathrm{df}=30, \mathrm{P}=0.16)$ or $C$ difficile infection $\left(\chi^{2}=25.54, \mathrm{df}=16\right.$, $\mathrm{P}=0.06)$. Evidence suggested some selection bias-that is, trusts with missing data for soap had lower rates of MRSA bacteraemia $(0.92,95 \%$ confidence interval 0.85 to 0.98$)$ and $C$ difficile infection $(0.88,0.86$ to 0.90$)$ and higher rates of MSSA bacteraemia $(1.082,1.04$ to 1.13$)$. Trusts with missing data for alcohol hand rub had lower rates of $C$ difficile infection $(0.58$, 0.54 to 0.63$)$. We found no selection bias in the type of trust.

\section{Discussion}

The study has shown that increasing procurement of alcohol hand rub and soap was associated with each phase of the Cleanyourhands campaign and that rates of MRSA bacteraemia and $C$ difficile infection fell while rates of MSSA bacteraemia rose. We found strong independent associations between increasing soap procurement and falling $C$ difficile infection rates throughout the study, and between increasing procurement of alcohol hand rub and falling rates of MRSA bacteraemia in the last year of the study. Increasing procurement was not the sole driver of these reductions, because publication of the Health Act 2006 and improvement team visits were both strong independent factors.

\section{Strengths and limitations of the study}

The strengths of the study were the inclusion of all trusts nationally over four years, including the period covering all phases of the campaign, collection of standardised objective proxy measures of hand hygiene (procurement of alcohol hand rub and soap), standardised collection of outcome data for key infections through national surveillance data, collection of potential confounding variables including the introduction and timing of other infection control interventions, and an appropriate analysis allowing control of confounding at trust level (instead of national level) to identify independent associations between use of hand hygiene consumables and hospital acquired infections.

Limitations of the study included the policy imperative to roll out the intervention quickly, which precluded more robust designs and the collection of potentially important but unavailable trust level data-in particular, antibiotic prescription and direct measures of hand hygiene compliance. However, although antibiotic data might confound reported associations between procurement and infection, it would require a strong correlation between rises in procurement and decreases in selected antibiotics to abolish these strong independent associations. Although procurement is only a proxy for hand hygiene compliance, nevertheless it is an objective measure collected in a comparable manner through NHS procurement across almost all trusts. Therefore, this objectivity minimises potential for observer bias and sampling bias, which are well recognised limitations of direct observation of hand hygiene compliance. ${ }^{22-24}$ Data were available from $87 \%$ and $74 \%$ of trusts for alcohol hand rub and soap, respectively, allowing for inclusion of the great majority of trusts in the analyses, which would have been difficult to achieve practically, through standardised measures of directly observed hand hygiene. The missing data would probably not have affected the trends and associations reported in the study.

\section{Impact of campaign on procurement of alcohol hand rub and soap}

Procurement of both alcohol hand rub and soap rose significantly in association with each phase of the campaign, the effect being greater for alcohol hand rub in the rollout phase, possibly indicating that campaign documents and guidance ${ }^{10}$ targeted use of the consumable, with few references to soap. ${ }^{26}$

A possible reinforcer of this effect is the publication of the Health Act 2006, which imposed legally binding duties on trusts, including provision of "adequate hand washing facilities and hand rubs," and mandated a rolling audit programme on hand hygiene that was embedded in local clinical governance frameworks. However, the increase in procurement of both alcohol hand rub and soap associated with the Health Act 2006 was either less than, or the same order of magnitude as, that associated with each campaign phase, and the act was published close to the final phase of the campaign. Therefore, the campaign could plausibly be interpreted as the main overall driver for the sustained increase in procurement, especially because the improvement team visits had no effect on this at individual trust level. This interpretation is consistent with findings from the National Audit Office that three years after completion of campaign roll out, $90 \%$ of acute trusts considered the campaign a top priority, with most of its main components implemented in nearly all wards. ${ }^{27}$

\section{Associations between procurement and infection data}

We found strong independent associations between increasing soap procurement and falling $C$ difficile infection rates throughout the study, and between increasing alcohol hand rub and falling MRSA bacteraemia rates in the last year of the study. These associations remained after adjustment for all other measured interventions and variables, and are biologically plausible and consistent with epidemiological models. ${ }^{28-31}$ The delayed association between procurement of alcohol hand rub and MRSA bacteraemia merits further investigation. The association might relate to a possible non-linear association between hand hygiene and MRSA prevalence, ${ }^{28}{ }^{29}$ or to long term changes in the community reservoir of MRSA carriage resulting from the intervention. ${ }^{3031}$ Other intervention studies ${ }^{32} 33$ have also reported possible threshold effects for hand hygiene compliance. The lack of association between MRSA bacteraemia and soap procurement could indicate the fact that soap is a less effective disinfectant than alcohol hand rub for $S$ aureus. The association between higher soap procurement and lower $C$ difficile infection is consistent with the removal of $C$ difficile spores by soap and water, but not by alcohol hand rub. ${ }^{34}$

The lack of association between procurement data and MSSA bacteraemia ${ }^{28} 2933$ could indicate that hand hygiene is less effective at interrupting endogenous transmission of infection 
(which is more likely for MSSA), than at interrupting the exogenous transmission (which in hospital settings is more likely to be associated with MRSA). The finding that non-specific interventions, such as hand hygiene, are more effective at reducing resistant rather than susceptible organisms when resistance is rare in the community is also consistent with predictions from mathematical models. ${ }^{35}$ The rise in MSSA bacteraemia during the study may reflect a generalised increase in community acquired staphylococcal infections reported in England ${ }^{36}$ and elsewhere. ${ }^{37} \mathrm{~A}$ high proportion of these bacteraemias are community acquired ${ }^{38}$ and thus less amenable to hospital based interventions. Notably, it was not possible with the available data to distinguish between hospital acquired and community acquired MSSA bacteraemia.

\section{National infection control interventions}

Increasing procurement was not the sole driver for the reductions in $C$ difficile infection and MRSA bacteraemia, because publication of the Health Act 2006 and trust visits by improvement teams were both strongly independently associated with the same reductions. Although our analysis controlled for these interventions, we cannot completely disentangle the relative effects through an observational study, a common problem when assessing the effectiveness of public health interventions in the real world. ${ }^{17}{ }^{18}$ The campaign took place within the context of a high profile political drive and other national interventions to reduce MRSA and $C$ difficile in particular. The campaign received central sustained funding and coordination. Government support for such campaigns has been identified as important elsewhere in Europe. ${ }^{22} 3940$ The Cleanyourhands campaign was the first national campaign on hand hygiene in the world, and the World Health Organization currently offers a very similar intervention as part of its Save Lives initiative. ${ }^{41}{ }^{42}$ Although caution should be exercised when extrapolating from the current study, its findings suggest that the campaign could offer a model for other countries to adopt or adapt.

Indeed, several evaluations at smaller scales of similar campaigns have found improved compliance to hand hygiene, increased procurement of alcohol hand rub, and an association of alcohol hand rub with MRSA reduction..$^{143-47}$ However, comparison with the existing scientific literature is difficult because this is the first national study of this size and duration, with this number of infection outcomes, that has considered hospital procurement of both soap and alcohol hand rub and has attempted to relate procurement to infection, accounting for multiple potential confounders.

\section{Research and policy implications}

This study, similar to other recent evaluations of public health interventions on a large scale, ${ }^{17} 18$ has implications for the design of future studies. Evaluation is essential but needs funding and considerable planning, to balance the competing needs of implementation and evaluation. ${ }^{18}$ Consideration should be given to staggering the roll out of interventions to facilitate higher quality designs ${ }^{48}$ and to extending national reporting to procurement and antibiotic prescribing data ${ }^{16}$ and to an increased range of infections. ${ }^{27}$ These factors would provide an improved infrastructure for future prospective evaluations of national interventions on infection control.

In conclusion, this study has shown that the national Cleanyourhands campaign was associated with increased procurement of alcohol hand rub and soap in each phase of the campaign. Higher procurement of soap and alcohol hand rub, publication of the Health Act 2006, and Department of Health improvement team visits to individual trusts were all strongly independently associated with reductions in MRSA bacteraemia and $C$ difficile infection. The relative contribution of soap and alcohol hand rub to these reductions is unclear, but their strong and independent associations remained after adjustment for all other interventions. The study suggests that national infection control interventions, including a hand hygiene campaign, undertaken in the context of a high profile political drive, can successfully reduce selected healthcare associated infections.

We thank Richard Horsfall (NHS Supply Chain), Tracey Prothero (Welsh Health Supplies, NHS Wales), Peter Phillips (Intercontinental Marketing Services), Ginny Edwards (UK Department of Health), infection control teams in all English and Welsh acute trusts, Katherine Wilson (National Patient Safety Agency), and the two referees for their helpful comments on the paper.

Contributors: All authors read and had input in the final version of the paper; had access to the data and analyses; and were involved in the conception, design, and conduct of the study over four years, and interpretation of the data. CF wrote the first draft of the manuscript. CF and JS collected and organised data with help from AC, MM, and GD. $A C$ did the data analysis with support from CF, JS, and SM. SPS wrote the original grant with input from $\mathrm{AH}, \mathrm{BC}$ ookson, BCooper, GD, AC, LT, AJ, SM, and JR.

Funding: The study received funding from the Patient Safety Research Programme (with donations from the trustees of the Royal Free London NHS Foundation Trust) and sponsorship from University College London. The funder had no role in the design, conduct, or analysis of the study. Competing interests: All authors have completed the Unified Competing Interest form at www.icmje.org/coi_disclosure.pdf (available on request from the corresponding author) and declare: the study received funding from the Patient Safety Research Programme (with donations from the trustees of the Royal Free London NHS Foundation Trust) and sponsorship from University College London; no financial relationships with any organisations that might have an interest in the submitted work in the previous 3 years; no other relationships or activities that could appear to have influenced the submitted work.

Ethical approval: The study protocol was approved by the multicentre research ethics committee (04MRE/10/66 Scotland).

Data sharing: Databases from the study are described on the website of the National Observation Study of the Effectiveness of the Cleanyourhands Campaign, with which data sharing arrangements can be entered into. The Infectious Diseases Research Network has agreed to facilitate this sharing of data, thus reaching a wider audience within the infection control research community.

1 Pratt R. The EPIC project: developing national evidence-based guidelines for preventing healthcare associated infections. $J$ Hosp Infect 2001;47(suppl):S1-82.

2 Curtis V, Cairnscross S. Effect of washing hands with soap on diarrhoea risk in the community: systematic review. Lancet Infect Dis 2003;3:275-81.

3 Stone SP, Teare L, Cookson BD. The guiding hand of our teachers (the evidence base for hand-hygiene). Lancet 2001;357:479-80.

4 Plowman R, Graves N, Griffin MA, Roberts JA, Swan AV, Cookson B, et al. The rate and cost of hospital-acquired infections occurring in patients admitted to selected specialties of a district general hospital in England and the national burden imposed. $J$ Hosp Infect 2001;47:198-209.

5 CDR Weekly. Staphylococcus aureus bacteraemia: England, Wales, and Northern Ireland: October to December 2003. Health Protection Agency, 2004. www.hpa.org.uk/cdr/archives/ 2004/staph_1204.pdf.

6 CDR Weekly. Results of the first year of mandatory Clostridium difficile reporting. Health Protection Agency, 2005. www.hpa.org.uk/cdr/archives/2005/cdr3405.pdf.

7 Report by the Comptroller and Auditor General. The management and control of hospital acquired infection in acute NHS trusts in England. National Audit Office, 2000. www.nao. org.uk/idoc. ashx? docld=02268660-34bb-455d-a72c-82dd3e248523\&version=-1.

8 Department of Health. NHS Plan Implementation Programme. HMSO, 2000.

9 Department of Health. Winning ways: working together to reduce healthcare associated infection in England: report by the chief medical officer. HMSO, 2003.

10 National Patient Safety Agency. Ready, steady, go. The full guide to implementing the cleanyourhands campaign in your trust. 2004. www.npsa.nhs.uk/EasySiteWeb/ GatewayLink.aspx?alld=5923. 


\section{What is already known on this topic}

Hand hygiene campaigns aim to reduce healthcare associated infections through sustained improvements in hand hygiene, although it is not known whether national campaigns are effective

The English and Welsh Cleanyourhands campaign was rolled out to all acute NHS trusts from January 2005, to reduce high levels of Staphylococcus aureus bacteraemia and Clostridium difficile infection

\section{What this study adds}

Each phase of the Cleanyourhands campaign was associated with increased hospital procurement of both alcohol hand rub and soap over a four year period

Increased procurement was strongly independently associated with reduced rates of meticillin resistant $S$ aureus bacteraemia and $C$ difficile infection, as were publication of the Health Act 2006 and trust visits by Department of Health improvement teams. These associations remained after adjustment for other interventions

11 National Patient Safety Agency. Flowing with the go. The complete year two campaign maintanence handbook for cleanyourhands partner trusts. The sequel to Ready, steady, go. 2006. www.npsa.nhs.uk.

12 National Patient Safety Agency. Achieving our aims: evaluating the results of the pilot Cleanyourhands campaign. 2004. www.npsa.nhs.uk/EasySiteWeb/GatewayLink.aspx? alld $=5924$.

13 Naikoba, S, Hayward A. The effectiveness of interventions aimed at increasing handwashing in healthcare workers-a systematic review. J Hosp Infect 2001;47:173-80.

4 Pittet D, Hugonnet S, Harbarth S, Mourouga P, Sauvan V, Touveneau S, et al. Effectiveness of a hospital-wide programme to improve compliance with hand hygiene. Lancet 2000;356:1307-12.

15 McGuckin M, Waterman R, Storr J, Bowler I, Ashby M, Topley K, et al. Evaluation of a patient empowering hand hygiene programme in the UK. $J$ Hosp Infect 2001;48:222-7.

16 Magiorakos AP, C Suetens, L Boyd, C Costa, R Cunney, V Drouvot, et al. National hand hygiene campaigns in Europe, 2000-2009. 2009. www.eurosurveillance.org/ViewArticle. aspx? Articleld $=19190$

17 Ng M, Gakidou E, Levin-Rector A, Khera A, Murray CJL, Dandona L. Assessment of population-level eff ect of Avahan, an HIV-prevention initiative in India. Lancet 2011;378:1643-52.

18 Boersma T, deZoysa I. Beyond accountability: learning from large scale evaluations. Lancet 2011;378:1610-1.

19 Department of Health. Saving lives: a delivery programme to reduce health care associated infection (HCAl) including MRSA. 2005. www.clean-safe-care.nhs.uk.

20 Department of Health. The Health Act 2006: code of practice for the prevention and control of healthcare associated infections. HMSO, 2006. www.dh.gov.uk/en/ Publicationsandstatistics/Publications/PublicationsPolicyAndGuidance/DH 081927.

21 Stevenson M, McClure R. Use of ecological study designs for injury prevention. Inj Prev 2005;11:2-4.

22 Magiorakos A P, Leens E, Drouvot V, May-Michelangelis L, Reichardt C, Gastmeier P, et al. Pathways to clean hands: highlights of successful hand hygiene implementation strategies in Europe. Eurosurveillance, 2010. www.eurosurveillance.org/ViewArticle.aspx? Articleld $=19560$

23 Schulze-Steinen H, Schiefer J, Koch A, Engels A, Lemmen SW. Compliance with hand hygiene on surgical, medical, and neurologic intensive care units: direct observation versus calculated disinfectant usage. Am J Infect Control 2009;37:835-41.

24 Joint Commission. Measuring hand hygiene adherence: overcoming the challenges. Join Commission, 2009

25 Stone SP, Cooper BS, Kibbler CC, Cookson BD, Roberts JA, Medley GF, et al. The ORION statement: guidelines for transparent reporting of outbreak reports and intervention studies of nosocomial infection. Lancet Infect Dis 2007;7:282-8.

26 Stone S, Slade R, Fuller C, Charlett A, Cookson B, Teare L, et al. Early communication does a national campaign to improve hand hygiene in the NHS work? Initial English and Welsh experience from the NOSEC study (National Observational Study to Evaluate the CleanYourHands Campaign). J Hosp Infect 2007;66;288-9.

27 Report by the comptroller and auditor general. Reducing healthcare associated infections in hospitals in England. National Audit Office, 2009. www.nao.org.uk/publications/0809/ reducing_healthcare_associated.aSpx.

28 Beggs CB, Shepherd SJ, Kerr KG. Increasing the frequency of hand washing by healthcare workers does not lead to commensurate reductions in staphylococcal infection in a hospital ward. BMC Infect Dis 2008;8:114.

29 Cooper BS, Medley GF, Scott GM. Preliminary analysis of the transmission dynamics of nosocomial infections:stochastic and management effects. J Hosp Infect 1999;43:131-47.

30 Cooper BS, Medley GF, Stone SP, Kibbler CC, Cookson BD, Roberts JA, et al. Methicillin-resistant Staphylococcus aureus in hospitals and the community:stealth dynamics and control catastrophes. Proc Natl Acad Sci U S A 2004;101:10223-8.

31 Bootsma MC, Diekmann O, Bonten MJ. Controlling methicillin-resistant Staphylococcus aureus: quantifying the effects of interventions and rapid diagnostic testing. Proc Nat/ Acad Sci USA 2006;103:5620-5.

32 Talon D, Thouverez, Bertrabd X. Is there a threshold above which handrub solution consumption is efficient for decreasing MRSA incidence. J Hosp Infect 2009;72:178-9.
33 Eveillard M, Kouatchet A, Rigaud A, Urban M, Lemarié C, Kowalczyk JP, et al. Association between an index of consumption of hand-rub solution and the incidence of acquired meticillin-resistant Staphylococcus aureus in an intensive care unit. $J$ Hosp Infect 2009;71:283-5.

34 Jabbar U, Leischner J, Kasper D, Gerber R, Sambol SP, Parada JP, et al. Effectiveness of alcohol-based hand rubs for removal of Clostridium difficile spores from hands. Infect Control Hosp Epidemiol 2010;31:565-70.

35 Lipsitch M, Bergstrom CT, Levin BR. The epidemiology of antibiotic resistance in hospitals: paradoxes and prescriptions. Proc Natl Acad Sci USA 2000;15;97:1938-43.

36 Wyllie DH, Peto TE, Crook D. MRSA bacteraemia in patients on arrival in hospital: a cohort study in Oxfordshire 1997-2003. BMJ 2005;33:992.

37 Lyytikäinen O, Ruotsalainen E, Järvinen A, Valtonen V, Ruutu P. Trends and outcome of nosocomial and community-acquired bloodstream infections due to Staphylococcus aureus in Finland, 1995-2001. Eur J Clin Microbiol Infect Dis 2005;24:399-404.

38 Hayward A, Knott F, Petersen I, Livermore DM, Duckworth G, Islam A, et al. Increasing hospitalizations and general practice prescriptions for community-onset staphylococcal disease, England. Emerg Infect Dis 2008. www.cdc.gov/EID/content/14/05/720.htm.

39 Leens $E$. Vous êtes en de bonnes mains: résultats de la troisième campagne nationale pour l'hygiène des mains dans les hôpitaux. Episcoop 2010;10:4. www.iph.fgov.be/ epidemio/epifr/episcoop/201001fr.pdf.

40 Behnke M, Moench N, Gastmeier P, Reichardt C, Geffers C. Increase of alcoholic hand rub consumption in 88 German hospitals participating in the national German hand hygiene campaign since the first 6 months of 2008 [poster 204]. Fifth Decennial International Conference on Healthcare-Associated Infections; 2010 March 18-22, Atlanta, GA, USA . http://shea.confex.com/shea/2010/webprogram/Paper1846.html.

41 World Health Organization. Save lives: clean your hands-WHO's global campaign. www. who.int/gpsc/5may/en

42 Allegranzi B, Sax H, ni Bengaly L, Richet H, Minta DK, Chraiti MN, et al. Successful implementation of the World Health Organization hand hygiene improvement strategy in a referral hospital in Mali, Africa. Infect Control Hosp Epidemiol 2010;31:133-41.

43 Johnson PD, Martin R, Burrell LJ, Grabsch EA, Kirsa SW, O'Keeffe J, et al. Efficacy of an alcohol/chlorhexidine hand hygiene program in a hospital with high rates of nosocomial methicillin-resistant Staphylococcus aureus (MRSA) infection. Med J Aust 2005;183:509-14.

44 Dierssen-Sotos T, Brugos-Llamazares V, Robles-Garcia M, Rebollo-Rodrigo H, as-A Ivarez $F$, Antoli' $n$-Juarez FM, et al. Evaluating the impact of a hand hygiene campaign on improving adherence. Am J Infect Control 2010;38:241-3.

45 Grayson ML, Jarvie LJ, Martin R, Johnson PDR, Jodoin ML, McMullan C, et al. Significant reductions in methicillin-resistant Staphylococcus aureus bacteraemia and clinical isolates associated with a multisite, hand hygiene culture-change program and subsequent successful statewide roll-out. Med J Aust 2008;188:633-40.

46 Kaier K, Hagist C, Frank U, Conrad A, Meyer E. Two time-series analyses of the impact of antibiotic consumption and alcohol-based hand disinfection on the incidences of nosocomial methicillin-resistant Staphylococcus aureus infection and Clostridium difficile infection. Infect Control Hosp Epidemiol 2009;30:346-53.

47 Vernaz N, Sax H, Pittet D, Bonnabry P, Schrenzel J, Harbarth S. Temporal effects of antibiotic use and hand rub consumption on the incidence of MRSA and Clostridium difficile. J Antimicrob Chemother 2008;62:601-7.

48 Craig P, Dieppe P, Macintyre S, Michie S, Nazareth I, Petticrew M. Developing and evaluating complex interventions: the new Medical Research Council guidance. BMJ 2008;337:a1655

Accepted: 02 April 2012

\section{Cite this as: BMJ 2012;344:e3005}

This is an open-access article distributed under the terms of the Creative Commons Attribution Non-commercial License, which permits use, distribution, and reproduction in any medium, provided the original work is properly cited, the use is non commercial and is otherwise in compliance with the license. See: http://creativecommons.org/licenses/bync/2.0/ and http://creativecommons.org/licenses/by-nc/2.0/legalcode. 


\section{Tables}

Table 1| Phases and key components of the Cleanyourhands campaign, and timing of other national interventions for infection control Cleanyourhands campaign*

Other national interventions

Phase 1: before roll out (1 July to 31 December 2004)

September 2004: patient safety alert issued, mandating placement of bedside alcohol

hand rub

Phase 2: roll out (1 January to 30 June 2005)

Roll out of campaign in four waves (January, March, April, June)

June 2005: Saving Lives campaign† launched

Phase 3: after roll out (1 July 2005 to 30 June 2008)

End of June 2006: campaign refreshed, with maintenance handbook reiterating main July 2005 onwards: acute hospitals register set up for Saving Lives campaign components of campaign, increased emphasis on auditing and feedback, use of soap for $C$ difficile infection, and further guidance on institutional engagement

November 2005: National targetł for MRSA bacteraemia announced

April 2006 onwards: acute hospital visits§ by improvement teams from the Department of Health

October 2006: Health Act 2006 passed by parliament

October 2007: campaign year 3 relaunched, with new posters designed in

collaboration with infection control teams

*National campaign implemented in 187 acute trusts in England and Wales, comprising placement of alcohol hand rub at patient's bedside, use of ward posters and patient empowerment materials, regular audits, and institutional engagement.

†Delivery programme designed to support acute hospitals in reducing common healthcare associated infections, by using a care bundle embedding infection control within a clinical governance framework (www.clean-safe-care.nhs.uk).

$\ddagger$ Target of $50 \%$ reduction in MRSA bacteraemia, to be achieved by each acute hospital over three years.

$\S$ Tailored support package to help hospitals deliver Saving Lives campaign and ensure that ultimate responsibility for healthcare associated infections lies with the chief executive. Although 103 hospitals were targeted because of high or rising levels MRSA bacteraemia or $C$ difficile infection, or probable failure to achieve MRSA bacteraemia target, a further 50 hospitals requested a visit.

ILegislation setting statutory criteria by which managers, chief executives, and boards ensure prevention and control of healthcare associated infections. 
Table 2| Associations from Poisson mixed effects model for $\mathbf{C}$ difficile infections

\begin{tabular}{|c|c|c|}
\hline Predictor & Estimated incidence rate ratio $(95 \% \mathrm{Cl})$ & $\mathbf{P}$ \\
\hline \multicolumn{3}{|l|}{ Procurement rate } \\
\hline Soap (per $\mathrm{mL}$ per bed day) & $0.993(0.990$ to 0.996$)$ & $<0.0001$ \\
\hline Alcohol hand rub (per $\mathrm{mL}$ per bed day) & $1.010(1.006$ to 1.013$)$ & $<0.0001$ \\
\hline \multicolumn{3}{|c|}{ Improvement team visit (for $C$ difficile infection) } \\
\hline Previous quarters & Reference & - \\
\hline Quarter before visit & $0.97(0.81$ to 1.16$)$ & 0.01 \\
\hline Quarter of visit & 0.96 (0.79 to 1.15$)$ & \\
\hline Quarter after visit & $0.90(0.74$ to 1.10$)$ & \\
\hline Subsequent quarters & 0.80 (0.71 to 0.90$)$ & \\
\hline Publication of Health Act 2006 & $0.75(0.67$ to 0.84$)$ & $<0.0001$ \\
\hline
\end{tabular}


Table 3| Associations from Poisson mixed effects model for mandatory MRSA bacteraemia

\section{Predictor}

Estimated incidence rate ratio $(95 \% \mathrm{Cl})$

Procurement rate of alcohol hand rub (per $\mathrm{mL}$ per day)

\begin{tabular}{lll}
\hline July 2004 to June 2005 & \multirow{2}{*}{$<0.0001$} \\
\cline { 1 - 2 } July 2005 to June 2006 & $1.003(0.998$ to 1.008$)$ & \\
\hline July 2006 to June 2007 & $1.002(0.997$ to 1.008$)$ & \\
\hline July 2007 to June 2008 & $0.990(0.985$ to 0.995$)$ & \multirow{2}{*}{0.03} \\
\hline Improvement team visit (for MRSA bacteraemia) & \\
\hline Previous quarters & Reference & \\
\hline Quarter before visit & $1.07(0.98$ to 1.17$)$ & \\
\hline Quarter of visit & $1.00(0.91$ to 1.11$)$ & \multirow{2}{*}{0.02} \\
\hline Quarter after visit & $1.02(0.92$ to 1.13$)$ & \\
\hline Subsequent quarters & $0.91(0.83$ to 0.99$)$ & \\
\hline Publication of Health Act 2006 & $0.86(0.75$ to 0.98$)$ & \\
\hline
\end{tabular}




\section{Figures}

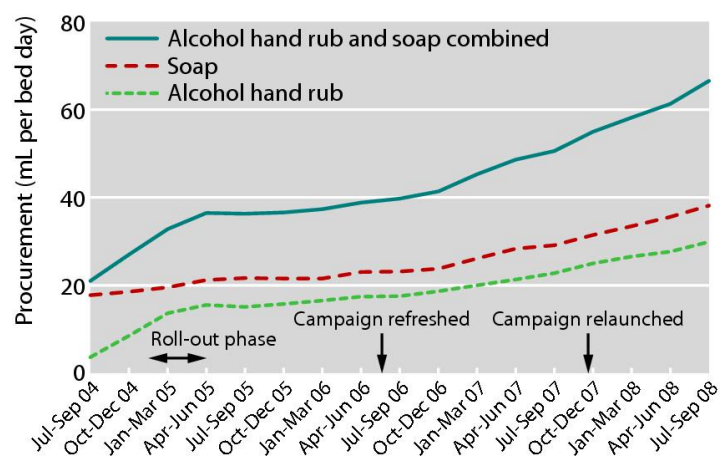

Fig 1 Estimated use of hand hygiene consumables, by quarter

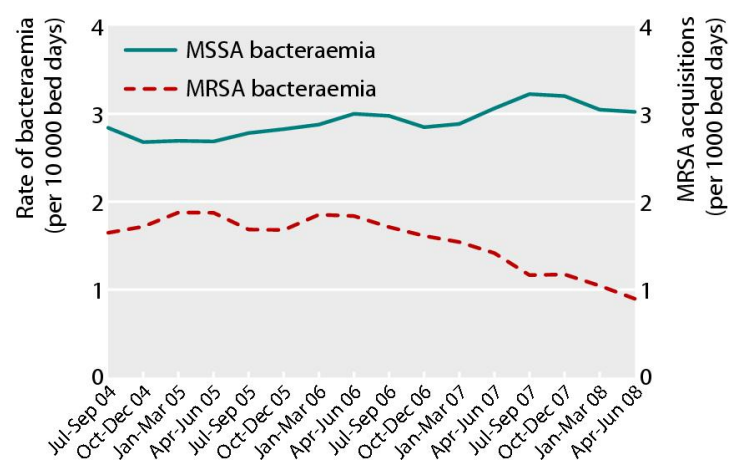

Fig 2 Estimated quarterly rate of bacteraemia (per 10000 bed days)

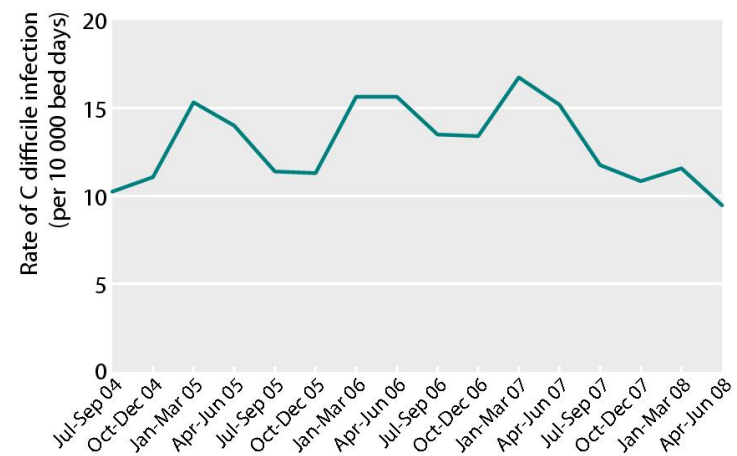

Fig 3 Estimated quarterly rate of $C$ difficile infection (per 10000 bed days) 


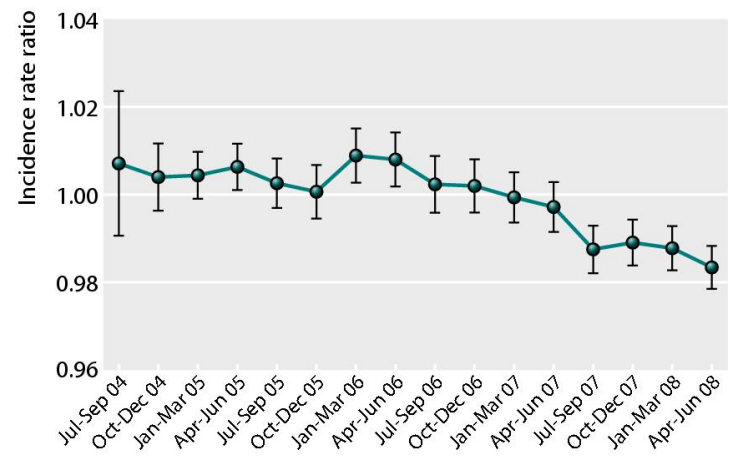

Fig 4 Estimated incidence rate ratios for MRSA bacteraemia for a $1 \mathrm{~mL}$ per bed day increase in alcohol hand rub, by quarter. Data are estimate (95\% confidence interval) 